\title{
Do left hand reaction time advantages depend on localising unpredictable targets?
}

\author{
Leah T. Johnstone ${ }^{1}$ and David P. Carey ${ }^{2 *}$ \\ ${ }^{1}$ Cognition Action and Perception Research Group, School of Psychology, University of East \\ Anglia, Norwich Research Park, Norwich, UK NR4 7TJ
${ }^{2}$ Perception, Action and Memory Research Group, School of Psychology, Bangor University, Bangor, UK, LL57 2AB \\ * Correspondence: D. Carey, email: d.carey@bangor.ac.uk
}

\begin{abstract}
:
Asymmetries in hand movements have routinely been attributed to properties of the two cerebral hemispheres. In right-handed participants, the non-dominant left hand tends to have shorter reaction times, with the dominant right hand achieving shorter movement durations as well as higher peak velocities. The root cause of the surprising left hand RT effect has been debated, largely in the context of right hemisphere specialization in attention, visuospatial abilities, or 'premotor' processes. Mieschke Elliott, Helsen, Carson, and Coull (2001, Cortex) and Barthélémy and Boulinguez (2002, Behav Brain Res) both tried to dissociate 'premotor' processes explaining the left hand RT advantage, using reaching paradigms where at least one condition required target detection, but no visually-guided aiming movement. Unfortunately the studies obtained conflicting results and conclusions. In the present study, we attempted to re-examine this kind of paradigm with methodological improvements, such as using a task with higher visuospatial demands. Our results demonstrate that whilst RTs are longer as movement complexity increases across three conditions, the left hand RT advantage is present across all conditions - and no significant interaction between hand and condition was found. No significant hand differences were found in peak velocity or duration. These results suggest that the left hand RT advantage cannot be due to movement planning advantages of the right hemisphere, and instead should be attributed to sustained attention/vigilance lateralisation to the right cerebral hemisphere.
\end{abstract}

Keywords:

Manual asymmetries, visually-guided reaching, reaction time, motor control, attention, vigilance 


\section{Acknowledgements:}

We are grateful to Bradley Dixon, Liz McManus, Lyam Sinar, and Arthur Norman for assistance with data collection. Llewellyn Morris, David Robinson, and David McKiernan provided expert technical assistance. This research was supported by Bangor University. 


\section{Introduction}

Many authors, for many years, have linked asymmetries in movements of the two hands to attributes of the two cerebral hemispheres (Bernard, Taylor, Seidler, 2011; Goble and Brown, 2008; Sainburg, 2014). Unsurprisingly, most of the empirical work focuses on the dominant and non-dominant hands of right-handed (dextral) participants, for whom cerebral asymmetry for language is best characterised and the most left lateralised (Binder et al., 1995; Carey and Johnstone, 2014; Corballis, 1997; Josse and Touzoyer-Mazoyer, 2004). In this group, when rapid visually-guided aiming movements are required, the dominant right hand tends to be superior in duration, peak velocity, and in some reports, endpoint accuracy. These dominant hand effects are usually interpreted in terms of models of motor control and left hemispheric specialisation, and have spawned many studies using reciprocal tapping tasks, often investigating the veracity of Fitt's Law, rather than attempting to uncover the mechanistic origins of the speed and accuracy advantages (Annett, Annett, Hudson and Turner, 1978; Todor and Kyprie, 1980; Todor and Cisneros; 1985).

The more intriguing finding in these manual asymmetry experiments in dextrals is that the non-dominant left hand tends to lead when it comes to reaction time (RT; Carson, Chua, Elliott, and Goodman, 1990; Carson, 1993; Elliott Roy, Goodman, Carson, Chua, and Maraj, 1993; Carson, Chua, Goodman, Byblow, and Elliott, 1995; Carson, 1996; Boulinguez, Nougier, and Velay, 2001ab; reviewed in Carey, Otto-de Haart, Buckingham, Dijkerman, Hargreaves, and Goodale, 2015). These left hand RT advantages are frequently obtained, and are usually accompanied with assertions that they relate to some right hemispheric process such as attention, visuospatial processing or "premotor" processes (usually not explained in any detail, and the latter interpretation comes dangerously close to describing the effect it is meant to explain). Richard Carson and his collaborators have attempted to manipulate the left hand RT advantage, to little effect, such that these scientists ended up concluding that hand differences are "transactional", and are remarkably dependent on particular experimental conditions that have not lent themselves to simple explanations of the phenomena (Carson, 1993; 1996; Carson, Elliot, Goodman, and Dickinson, 1990: Carson, Goodman and Elliott, 1992; Elliott et al., 1993). Undeterred by these efforts, one of us has undertaken several attempts to attenuate or exaggerate this left hand advantage, by manipulating visuospatial or attentional demands, while keeping the sensorimotor requirements of the tasks equivalent. These efforts, to date, have been remarkably unsuccessful (Carey et al., 2015).

Nevertheless, one manipulation that could help unpack the potential right hemispheric 
contribution to the advantage has been explored by two different laboratories. Both Mieschke Elliott, Helsen, Carson, and Coull (2001) and Barthélémy and Boulinguez (2002) measured manual asymmetries in RT in conditions where participants had to reach to unpredictable target locations, or give a simpler finger lift or key press response when target onset was detected. The logic here was that both conditions relied on whatever visuospatial/ attention processes are required for target detection, but that only one condition required planning of a complex movement.

Mieschke et al. (2001) compared one group of participants who reached to a target (in one of five possible locations on a horizontal table top), to another who other simply lifted their hand from the start position upon target detection. RTs in the lift group were faster than those in the reach group, and no hand difference was found in the lift group, whereas a left hand RT advantage was present in the reach group. However, this effect was only present in left hemispace. Most hand advantages (i.e. main effects in ANOVA designs) are accounted for by larger ipsilateral space advantages in that hand (see Carey et al., 2015; and Carey and Liddle, 2013 for discussion); this difference between the hands in left space is typically substantial enough to drive a main effect of hand. With respect to peak velocities (PVs) and movement durations of the reach group, significant hand $x$ space interactions were found where each hand tended to benefit when reaching into ipsilateral space. The authors conclude that the left hand RT advantage, and the longer RTs in the reaching group data, are a result of right hemispheric advantages in early stages of movement planning (supporting the movement planning hypothesis - see Carson, 1996). In many of these papers, where premotor processing/movement planning is suggested as an explanation for the left hand RT effect, it is rare for authors to specify what aspects are being controlled. That is, these authors may believe that the specific muscular contractions required for a particular reach employ more right hemispheric involvement, or that some premotor specification of specific target location must depend more on right hemispheric mechanisms. In any case, their finding suggests that the left hand RT effect depends upon a visually-guided reach to a target location. A year later, evidence was published which suggests that detecting the onset of target is sufficient for left hand RT advantages.

Barthélémy and Boulinguez (2002) conducted a similar study, where target detection RTs were recorded via a keypress response, compared with reaching movements to the same targets. Two groups of participants were presented with two possible target locations either side of a fixation cross on a computer monitor. In both of these conditions, the left hand had significantly shorter RTs. The authors conclude that these data support the hypothesis that the left hand RT 
effect is due to advantages of the right hemisphere in "allocation of visuospatial attention", and the direct access that the left hand has to this hemisphere. Although unstated, this interpretation suggests that even detecting the onset of a target requires a covert movement of visuospatial attention to the target location. A large literature on cueing effects demonstrates that attention can be moved "covertly" (Posner and Peterson, 1990). Nevertheless, visual search experiments show that identifying the presence of a target along a single dimension can be performed in a parallel non-linear fashion (e.g. Treisman and Gormican, 1988), which does suggest that "transients", such as suddenly appearing high contrast singleton targets can pop out "preattentively", but this issue is not without controversy (Bekkering and Pratt, 2004; Jonikaitis, Schubert and Deubel, 2010; Long and Ma-Wyatt, 2014).

In any case, both of the above studies could be improved methodologically. The use of between-subjects designs for the two types of task (lift/press versus reach) brings with it all the usual criticisms relating to individual variability, and in the case of Mietschke et al. (2001) coupled with a relatively small sample size in each group (in this case only 11 participants). The left hand RT advantage is subtle, usually only around $10 \mathrm{msec}$, and only obtained in $\sim 65-70 \%$ of any sample of right handers. In Carey et al. (2015), a precision analysis recommended by Cumming (2012) suggests that to get a statistically reliable left hand RT effect at least 24 participants should be tested.

More critical to the research question of these investigations, neither study employed a reaching paradigm that was particularly taxing for visuospatial attention/localisation processes; namely both studies only used one or two targets on either side of fixation. After practice trials (and initial experimental trials), participants can easily associate a particular motor response/ amplitude of movement, with a particular visual stimulus. Furthermore, the targets varied along only one dimension (e.g. the horizontal meridian). Any neural systems which are necessary for producing accurate movements in peripersonal space clearly have to be sensitive to target positions in multiple dimensions (Carey, Sahraie, Trevethan and Weiskrantz, 2008). Whether the left hand RT advantage is driven by planning complex movements or visuospatial advantages, increased task demands in terms of number of targets and their locations would be the best method to test these theories.

Additionally, in Barthélémy and Boulinguez (2002), targets were presented on an upright computer monitor. As there was no mention of physical restraint or protection of the monitor, it seems unlikely that participants would make highly ballistic movements to such a screen. Instead, at least some of their participants in the reach group may have approached the final target positions 
tentatively in order to land without perturbing the monitor in any way. Although we know of no systematic study which examines manual asymmetries in kinematics where movement speed is varied by instructions, there is evidence that many sensory motor systems are sensitive to accuracy, speed, or speed and accuracy instructions (Fisk and Goodale, 1989).

A final modification to the current design, was the addition of a condition where target onset was a go signal, for a pointing movement to the former fixation cross position. This condition is intermediate to detection and point to target tasks in at least two ways. First, an aiming movement to the target surface is required, unlike in the detection tasks used by Mieschke et al (2001) and Barthélémy and Boulinguez (2002). Second, it may be that premotor theories of left hand reaction time advantages do not depend upon de novo computation of reach end point. In other words, as in earlier studies on one target advantages (e.g. Adam et al., 2000; Khan, Franks, and Goodman, 1998) a larger amplitude movement is required, but the reach end point is known.

The present study attempts to uncouple the mechanisms behind the left hand reaction time advantage, and builds upon previous literature in three ways. Firstly, a repeated measures design was employed, so that the different movement conditions were directly comparable. Secondly, as well as lift and point to target conditions, we included a condition where participants pointed to the fixation cross location on each trial. This intermediate step between the two previously used conditions allows us to compare the effects of the uncertainty of the movement endpoint versus the uncertainty of the target location on RT. Finally, a large, two-dimensional target grid, with 24 unique target positions (compared to two or five in the previous studies) was used, to ensure unpredictability of target locations, and therefore an increased demand on any localisation/visuospatial attention processes. If these processes support the left hand due to being more right hemisphere dominant, then you would expect a left hand reaction time advantage across all conditions of the study. If the movement planning hypothesis explains hand differences in RT, then the left hand advantage should increase as the task increases in complexity.

\section{Methods}

Participants

Participants were 24 undergraduates and postgraduates (10 male) from the School of Psychology at Bangor University. Participants were right handed for writing, and had a mean score of 27.2 (maximum $=+30$ ) on the modified version of the Waterloo Handedness Questionnaire (WHQ; Steenhuis and Bryden, 1989). Mean age was 20.7 years (S.D.=1.4). All procedures were approved by the Ethics Committee of the School of Psychology at Bangor 
University.

\section{Apparatus and stimuli}

Reaching movements were recorded with a Qualisys Oqus motion capture system with a three camera set-up (Qualisys, Sweden) recording at a frequency of $240 \mathrm{~Hz}$ (allowing for accuracy within $4 \mathrm{msec}$ ). To estimate the spatial accuracy of our camera system, ten trials were collected of a static infrared marker (with a duration of five seconds). The biggest difference in the position data across trials was $3,2.8$, and $3.3 \mathrm{~mm}$ in the $x, y$ and $z$ dimensions. The 24 targets used were white filled circles with a diameter of $1 \mathrm{~cm}$ (although participants' height affected individual viewing distance, we estimated an average viewing height of $55 \mathrm{~cm}$, which would give the targets a visual angle of $\left.1^{\circ}\right)$. The target grid was arranged with a horizontal meridian (10 targets), two targets $20 \mathrm{~cm}$ above and below fixation, and three targets in the remaining quadrants (see figure 1). Targets were displayed on a black background.

These stimuli were presented to the underside of a large, sturdy, bespoke glass top table $(140 \times 106 \mathrm{~cm})$ using a short-throw Sanyo PDG-DWL2500 Multimedia Projector. The projector mirrored a computer running EPrime 2.0 software (Psychology Software Tools, Pittsburgh, PA) to present the stimuli, and a second computer collected infrared marker data. The start position for participants was a Velcro pad located in the centre of the closest table edge, $30 \mathrm{~cm}$ from the central fixation point. The most peripheral of the targets were $30 \mathrm{~cm}$ (or $30^{\circ}$ ) lateral to fixation. An infrared reflective marker with a diameter of $1 \mathrm{~cm}$ was attached to the nail of participants' index fingers using adhesive Velcro.

\section{FIGURE 1}

Fig 1 - A representation of the two-dimensional target grid. The central fixation cross was 30 $\mathrm{cm}$ from the nearest edge of the display table to the participant

\section{Procedure}

Participants were seated oriented to the middle of the table. A central fixation cross was presented at the start of every trial. A verbal cue from the experimenter would precede the start of each trial to ensure participants were prepared. The experimenter would then initiate the trial with 
an audible key-press; the fixation cross would disappear, a variable delay of 200, 400, or $600 \mathrm{msec}$ would follow, before finally the target would appear for $400 \mathrm{msec}$. This brief duration has been used in previous experiments to encourage rapid responding (Carey Hargreaves and Goodale, 1996). A trigger was sent to the cameras to begin collection simultaneously with target presentation.

Three conditions were explained to participants: the lift condition, point fixation condition, and point target condition. In the lift condition, participants were required to lift their index finger to shoulder height, as quickly as they could, on detection of target onset. In the point fixation condition, participants had to point to the location of the fixation point (extinguished at target onset) when they detected target onset. Finally, in the point to target condition, participants pointed to the location of the target. For this latter condition, we emphasized that speed was more important than endpoint accuracy (see figure 2 for images of each of these trial types in our lab set up).

Participants completed 48 trials of each condition with each hand, resulting in 288 trials overall. Trials were presented in pseudorandomised blocks, ensuring unpredictability of target location, and that both hands reached to the same locations in the point target condition (and would therefore be comparable). Each block contained 48 trials, within which each target was presented twice. Participants alternated hands between each block, and starting hand/starting condition were counterbalanced across participants (condition order was always lift $>$ point fixation $>$ point target, or point target $>$ point fixation $>$ lift).

\section{FIGURE 2}

Fig 2 - A depiction of the various task conditions. All trials in all conditions began with the presence of a fixation cross which subsequently disappeared 200, 400 or $600 \mathrm{msec}$ before a target appeared. In the lift condition, participants simply lifted their hand; in the point fixation condition, they reached to where the fixation cross had been previously; and finally in the point target condition they would reach to where the target appeared 


\section{Analysis}

We used a suite of LabVIEW programs (3Wave) for data processing. Raw position data were differentiated into a three-dimensional format and filtered with a $10 \mathrm{~Hz}$ low-pass filter, to remove high frequency noise from the data. From the filtered files we extracted RT (i.e. msec from target onset to movement onset), PV ( $\mathrm{mm} / \mathrm{sec})$, and movement duration (msec). A velocity of $30 \mathrm{~mm} / \mathrm{sec}$ was considered as a threshold for both movement onset and offset (Carey and Liddle, 2013). Side of space was not included as a factor in these analyses as the target grid is symmetrical and therefore this variable is controlled for.

Similarly to Mieschke et al. (2001) for the lift hand condition we only analysed RT data, whereas in the conditions that actually required a reaching movement we examined RT as well as peak velocity (PV) and duration of the movement. Hand $\mathrm{x}$ condition repeated measures ANOVAs were run separately on each dependent measure. The alpha criterion for follow up $t$-tests was adjusted by dividing .05 by the number of comparisons being tested. It was predicted that if the left hand RT advantage was actually dependent on reaching to a target, then a hand $\mathrm{x}$ condition interaction should occur in the RT analysis. On the recommendation of an anonymous reviewer, we also ran a repeated-measures ANOVA with hemispace as a third factor (results appear in Supplementary materials). It did not interact with hand, condition or condition by hand.

\section{Results}

The distributions of all six hand by condition cells are not significantly different from normality as assessed by the Shapiro Wilks test (Shapiro \& Wilk, 1965). We also report an additional effect size measure, generalized partial eta squared $\left(\eta^{2} \mathrm{G}\right)$, as recommended by Bakeman (2005) for repeated measures designs, but also report it as well as the more commonly used partial eta squared $\left(\eta_{\mathrm{p}}{ }^{2}\right)$, as advised by Lakens (2013). A 2x3 ANOVA was run on the RT data comparing hands (left/right) and conditions (lift/point fixation/point target). A significant main effect of hand was found $\left(F(1,23)=21.93, p<.001, \eta_{\mathrm{p}}{ }^{2}=.49, \eta^{2}{ }_{\mathrm{G}}=.03\right)$, showing the traditionally reported left hand reaction time advantage, which was $11 \mathrm{msec}$ on average. Post hoc paired-samples t-tests revealed a significant left hand advantage in the lift condition $(t(23)=2.41, p<.03)$, the point fixation condition $(t(23)=3.47, p=.002)$, and the point target condition $(t(23)=3.26, p=.003)$. In this sample of 24 participants, 19 had a numerical left hand RT advantage (79.2\%), four had a right hand RT advantage, and one had equivalent RTs across hands.

A significant main effect of condition was also found $\left(F(2,46)=21.14, p<.001, \eta_{\mathrm{p}}{ }^{2}=.48\right.$, $\left.\eta^{2}{ }_{G}=.15\right)$. Pairwise comparisons using Bonferroni adjustment for multiple comparisons found that 
all comparisons between conditions were significantly different, with the lift condition RTs being significantly faster than the point fixation (12 msec, $p<.02)$ and point target (32 msec, $p<.001)$ conditions, and the point fixation condition resulting in faster RTs than the point target condition (20 msec, $p<.001$ - see figure 3 for hand $\mathrm{x}$ condition $\mathrm{RT}$ data). The hand by condition interaction was not significant $\left(\mathrm{F}(2,46)=0.28, \mathrm{p}>.05, \eta_{\mathrm{p}}{ }^{2}=.01, \eta^{2}{ }_{\mathrm{G}}=.001\right)$.

\section{FIGURE 3}

Fig 3 - Mean RTs for both hands across all three conditions. Clear main effects of both hand and condition are present, but there is no interaction

For completeness we also calculated averages for the two dependent variables that tend to favour the right hand in dextral samples, movement duration and peak velocity, in case they interact in some interesting way with our three conditions. Additional ANOVAs were run on PV and duration measures, but for these analyses, the lift condition was not included, given the stark differences in movement constraints between lifting and the two other tasks. Of course, there were more varied movement distances required in the point target condition than the point fixation condition, but on average these distances were $34.5 \mathrm{~cm}$, which is not too dissimilar to the $30 \mathrm{~cm}$ reach required in the fixation point condition (although the additional distance equates to $\sim 1 / 6^{\text {th }}$ of the fixation point reaches). The PV analysis revealed no significant interaction or main effect of hand, but a significant main effect of condition $\left(F(1,23)=134.29, p<.001, \eta_{\mathrm{p}}{ }^{2}=.85, \eta^{2} \mathrm{G}=.15\right)$, with PVs averaging $303 \mathrm{~mm} / \mathrm{sec}$ higher in the point target condition $(2000 \mathrm{~mm} / \mathrm{sec})$ than the point fixation condition $(1697 \mathrm{~mm} / \mathrm{sec})$. Similarly in the duration analysis, only a main effect of condition was found $\left(F(1,23)=26.62, p<.001, \eta_{\mathrm{p}}{ }^{2}=.54, \eta^{2}{ }_{\mathrm{G}}=.08\right)$, with durations averaging 21 msec shorter in the point fixation condition $(348 \mathrm{msec})$ than the point target condition $(369 \mathrm{msec}$ - see figure 4 for PV and duration data as a function of hand). 
Fig 4 - Mean PVs and movement durations across the point fixation and point target conditions. A main effect of condition is present in both dependent measures, but no significant effect of hand was found

\section{Discussion}

The results from the experiment are fairly unequivocal. In this sample, left hand RT advantages do not differ across lift, point fixation and point target blocks, in spite of a quite predictable increase in RT across those conditions. These results replicate the results of Barthélémy and Boulinguez (2002) with, in our opinion, improvements to their design. In both studies, statistically significant reaction time advantages for the left hand did not depend on making a visually-guided movement to a suddenly appearing visual target. By contrast, Mieschke et al. (2001) only find the left hand RT advantage in a visually guided pointing condition. Both of these previous studies utitlised between-subjects designs, which will inevitably be subject to participant-specific sources of noise and cannot capitalise on the difference score approach used in repeated measures analyses, such as those of the current study. In fact, our previous analyses of the presence and absence of the left hand RT effect suggest that it is relatively small in magnitude (about $7 \mathrm{msec}$ on average), and it is not always reliably obtained in samples smaller than the kind we used here (Carey et al., 2015); between-subjects approaches would need considerably larger numbers of participants.

We have been struck by how infrequently investigators have attempted to accentuate or attenuate the left hand RT advantage, as a first pass at trying to understand its source. In past studies our lab has tended to shy away from premotor explanations (which in many instances do little more than describe the effect they are meant to explain). Instead, we have always favoured explanations associated with functions lateralized to the right hemisphere. For example, right hemisphere specialisation for attentional mechanisms have been well known since the mid- $20^{\text {th }}$ century (e.g. McFie, Piercy and Zangwill, 1950). Similarly, links of the right hemisphere to visuospatial processing also have a long and rich neuropsychological history (De Renzi, 1982). Nevertheless, several of our previous attempts to manipulate attention, and/or visuospatial processing, using tasks which varied the number of targets, required bisecting two targets vs pointing to a single target, and so on, have failed to influence the left hand advantage (Carey et 
al., 2015).

It is almost impossible in paradigms such as this, when, by definition, targets have to appear at unpredictable locations to completely rule out contributions of visuospatial attention, i.e. an attentional resource that needs to be moved, or is moved involuntarily by the appearance of a visual transient. Such "movements", in some spatial attention sense, may also occur even when the spatial location of the target is irrelevant for the response (as in the point fixation and lift conditions in our study). We do know that accurate saccadic and manual movements can be made to targets without any sort of conscious attention or awareness of target onset, from cases of patients with blindsight (reviewed in Carey et al., 2008; Danckert and Rossetti, 2005). It may be of course, that spatially selective mechanisms "move" to target locations covertly, even in a scotoma, however, such suggestions take us dangerously close to the now discredited idea of premotor theories of attentional shifts. We have known for many years that even in detection tasks, valid and invalid cueing (implying spatial movement of the focus of attention) manipulates our reaction times exactly as predicted. These cueing effects do not appear to interact in meaningful ways with left hand RT advantages, at least in the data of Barthélémy and Boulinguez (2002), but replication with a larger number of target conditions, as well as a within-subjects design might be required.

In conclusion, these results support the idea of a vigilance explanation of the left hand RT advantage. This feature, usually related to the right hemisphere only in a rather circumscribed part of the neurological literature, remains relatively unexplored in cognitive neuroscience and experimental neuropsychology. Although difficult to parametrically manipulate, vigilance could play a much larger role in experimental neuropsychology and cognitive neuroscience. For example, asymmetries favouring the right hemisphere are completely unexplored in left-handers (except for some early, suspiciously underpowered studies of face processing asymmetries, e.g. Heller \& Levy, 1981--a group whose asymmetry for language is quite perplexing from a sensorimotor control perspective.

\section{References}

Adam JJ, Nieuwenstein JH, Huys R, Paas FG, Kingma H, Willems P, Werry M (2000) Control of rapid aimed hand movements: the one-target advantage. J Exp Psychol Human 26(1):295-312. http://dx.doi.org/10.1037/0096-1523.26.1.295 
Annett J, Annett M, Hudson PTW, Turner (1979) The control of movement in the preferred and non-preferred hands. Q J Exp Psychol 31(4):641-652.

http://dx.doi.org/10.1080/14640747908400755

Bakeman R (2005) Recommended effect size statistics for repeated measures designs. Behavior Research Methods, 37(3), 379-384. http://dx.doi.org/10.3758/BF03192707

Barthélémy S, Boulinguez P (2001) Manual reaction time asymmetries in human subjects: the role of movement planning and attention. Neurosci Lett, 315(1):41-44.

http://dx.doi.org/10.1016/S0304-3940(01)02313-8

Barthélémy S, Boulinguez P (2002) Orienting visuospatial attention generates manual reaction time asymmetries in target detection and pointing. Behav Brain Res 133(1):109-116. http://dx.doi.org/10.1016/S0166-4328(01)00446-6

Bernard JA, Taylor SF, Seidler RD (2011) Handedness, dexterity, and motor cortical representations. J Neurophysiol 105(1):88-99. http://dx.doi.org/10.1152/jn.00512.2010

Bekkering H, Pratt J (2004) Object-based processes in the planning of goal-directed hand movements. Q J Exp Psychol 57(8):1345-1368. http://dx.doi.org/10.1080/02724980343000765

Binder JR, Rao SM, Hammeke TA, Frost JA, Bandettini PA, Jesmanowicz A, Hyde JS (1995) Lateralized human brain language systems demonstrated by task subtraction functional magnetic resonance imaging. Arch Neurol 52(6): 593-601. http://dx.doi.org/10.1001/archneur.1995.00540300067015

Boulinguez P, Nougier V, Velay JL (2001a) Manual asymmetries in reaching movement control. I: study of right-handers. Cortex 37(1):101-122. http://dx.doi.org/ 10.1016/S00109452(08)70561-6

Boulinguez P, Nougier V, Velay JL (2001b) Manual asymmetries in reaching movement control. II: study of left-handers. Cortex 37(1):123-138. http://dx.doi.org/10.1016/S0010- 
9452(08)70562-8

Carey DP, Hargreaves EL, Goodale MA (1996) Reaching to ipsilateral or contralateral targets: within-hemisphere visuomotor processing cannot explain hemispatial differences in motor control. Exp Br Res 112:496-504. http://dx.doi.org/10.1007/BF00227955

Carey DP, Otto-de Haart EG, Buckingham G, Dijkerman HC, Hargreaves EL, Goodale MA (2015) Are there right hemisphere contributions to visually-guided movement? Manipulating left hand reaction time advantages in dextrals. Front Psychol, 6. 1203. http://dx.doi.org/10.3389/fpsyg.2015.01203

Carey DP, Johnstone LT (2014) Quantifying cerebral asymmetries for language in dextrals and adextrals with random-effects meta analysis. Front Psychol 5:1128. http://dx.doi.org/10.3389/fpsyg.2014.01128

Carey DP, Sahraie A, Trevethan CT, Weiskrantz L (2008) Does localisation blindsight extend to two-dimensional targets? Neuropsychologia 46:3053-3060. http://dx.doi.org/10.1016/j.neuropsychologia.2008.06.015

Carey DP, Liddle J (2013) Hemifield or hemispace: what accounts for the ipsilateral advantages in visually-guided aiming? Exp Br Res 230:323-331. http://dx.doi.org/10.1007/s00221-013-3734-7

Carson RG (1993) Manual asymmetries: Old problems and new directions. Hum Mov Sci 12(5): 479-506. http://dx.doi.org/10.1016/0167-9457(93)90001-6

Carson RG, Chua R, Elliott D, Goodman D (1990) The contribution of vision to asymmetries in manual aiming. Neuropsychologia 28(11):1215-1220. http://dx.doi.org/10.1016/00283932(90)90056-T

Carson RG, Chua R, Goodman D, Byblow WD, Elliott D (1995) The preparation of aiming movements. Brain Cognition 28(2):133-154. http://dx.doi.org/doi:10.1006/brcg.1995.1161 
Carson RG (1996) Putative right hemisphere contributions to the preparation of reaching and aiming movements. Hand preference and performance in skilled and unskilled activities. In: Elliot D, Roy EA (eds) Manual Asymmetries in Motor Performance, Boca Raton, FL, pp 159172.

Carson RG, Elliott D, Goodman D, Dickinson J (1990) Manual asymmetries in the reproduction of a 3-dimensional spatial location. Neuropsychologia 28:99-103.

http://dx.doi.org/10.1016/0028-3932(90)90090-B

Carson RG, Goodman D, Chua R Elliot D (1993) Asymmetries in the regulation of visually guided aiming. J Mot Behav 25,:21-32. http://dx.doi.org/10.1080/00222895.1993.9941636

Corballis, MC (1997) The genetics and evolution of handedness. Psychol Rev, 104:714-727. http://dx.doi.org/10.1037/0033-295X.104.4.714

Corbetta M, Shulman GL (2002) Control of goal-directed and stimulus-driven attention in the brain. Nat Rev Neurosci, 3(3):201-215. http://dx.doi.org/10.1038/nrn755

Danckert J, Rossetti Y (2005) Blindsight in action: what can the different sub-types of blindsight tell us about the control of visually guided actions? Neurosci Biobehav Rev 29(7): 1035-1046. http://dx.doi.org/10.1016/j.neubiorev.2005.02.001

DeRenzi E (1982) Disorders of space exploration and cognition. John Wiley and Sons, NY.

Dorris MC, Munoz DP (1995) A neural correlate for the gap effect on saccadic reaction times in monkey. J Neurophysiol 73(6):2558-2562.

Elliott D, Roy EA, Goodman D, Carson RG, Chua R, Maraj BKV (1993) Asymmetries in the preparation and control of manual aiming movements. Can J Exp Psychol 47:570-589. http://dx.doi.org/10.1037/h0078856

Fisk JD, Goodale MA (1989) The effects of instructions to subjects on the programming of visually directed reaching movements. J Motor Behav 21(1):5-19. 
http://dx.doi.org/10.1080/00222895.1989.10735461

Fisk JD, Goodale MA (1989) The effects of instructions to subjects on the programming of visually directed reaching movements. J Motor Behav 21(1):5-19. http://dx.doi.org/10.1080/00222895.1989.10735461

Goble DJ, Brown SH (2008) The biological and behavioral basis of upper limb asymmetries in sensorimotor performance. Neurosci Biobehav R 32(3):598-610.

http://dx.doi.org/10.1016/j.neubiorev.2007.10.006

Goodale MA (1990) Brain asymmetries in the control of reaching. In: Goodale M (ed) Vision and action: the control of grasping. Ablex Publishing, Norwood,NJ, pp 14-32

Heller W, Levy J (1981) Perception and expression of emotion in right-handers and left-handers. Neuropsychologia, 19, 263-272. http://dx.doi.org/10.1016/0028-3932(81)90110-X

Jonikaitis D, Schubert T, Deubel H (2010) Preparing coordinated eye and hand movements: dual-task costs are not attentional. J Vision 10(14):23-23. http://dx.doi.org/10.1167/10.14.23

Josse G, Tzourio-Mazoyer N (2004) Hemispheric specialization for language. Brain Res Rev 44(1):1-12. http://dx.doi.org/10.1016/j.brainresrev.2003.10.001

Khan MA, Franks IM, Goodman D (1998) The effect of practice on the control of rapid aiming movements: Evidence for an interdependency between programming and feedback processing. Q J Exp Psychol 51(2):425-443. http://dx.doi.org/10.1080/713755756

Kingstone A, Klein R (1993) Visual offset facilitates saccadic latency: does pre-disengagement of visuo-spatial attention mediate this gap effect? J Exp Psychol Human 19:1251-1265. http://dx.doi.org/10.1037/0096-1523.19.6.1251

Lakens D (2013) Calculating and reporting effect sizes to facilitate cumulative science: a practical primer for t-tests and ANOVAs. Front Psychol, 4, 863. http://dx.doi.org/ 
10.3389/fpsyg.2013.00863

Long H, Ma-Wyatt A (2014) The distribution of spatial attention changes with task demands during goal-directed reaching. Exp Brain Res 232(6):1883-1893.

http://dx.doi.org/10.1007/s00221-014-3880-6

McFie J, Piercy M, Zangwill OL (1950) Visual-spatial agnosia associated with lesions of the right cerebral hemisphere. Brain 73: 167-190. http://dx.doi.org/10.1093/brain/73.2.167

Mieschke PE, Elliott D, Helsen WF, Carson RG, Coull JA (2001) Manual asymmetries in the preparation and control of goal-directed movements. Brain Cognition 45(1):129-140. http://dx.doi.org/10.1006/brcg.2000.1262

Posner MI (1978) Chronometric explorations of mind. Hillsdale, NJ: Lawrence Erlbaum.

Posner MI, Peterson SE (1990) The attention system of the human brain. Ann Rev Neurosci 13:25-42. http://dx.doi.org/ 10.1146/annurev.ne.13.030190.000325

Rueckert L, Grafman J (1996) Sustained attention deficits in patients with right frontal lesions. Neuropsychologia 34(10):953-963. http://dx.doi.org/10.1016/0028-3932(96)00016-4

Sainburg RL (2014) Convergent models of handedness and brain lateralization. Front Psychol, 5(1092):1-14. http://dx.doi.org/10.3389/fpsyg.2014.01092

Shapiro, S. S., \& Wilk, M. B. (1965). An analysis of variance test for normality (complete samples). Biometrika, 52(3/4), 591-611. http://dx.doi.org/10.2307/2333709

Steenhuis RE, Bryden MP (1989) Different dimensions of hand preference that relate to skilled and unskilled activities. Cortex 25:289-304. http://dx.doi.org/10.1016/S00109452(89)80044-9

Todor JI, and Kyprie PM (1980). Hand differences in the rate and variability of rapid tapping. J Mot Behav 12(1):57-62. http://dx.doi.org/10.1080/00222895.1980.10735205 
Todor JI and Cisneros J (1985). Accommodation to increased accuracy demands by the right and left hands. J Mot Behav, 10:295-300. http://dx.doi.org/10.1080/00222895.1985.10735354

Treisman A, Gormican S (1988) Feature analysis in early vision: evidence from search asymmetries. Psychol Rev 95(1):15-48. http://dx.doi.org/10.1037/0033-295X.95.1.15

Weissman DH, Roberts KC, Visscher KM, Woldorff MG (2006) The neural bases of momentary lapses in attention. Nat Neurosci 9(7):971-978. http://dx.doi.org/10.1038/nn1727

Wilkins AJ, Shallice T, McCarthy R (1987) Frontal lesions and sustained attention. Neuropsychologia 25(2):359-365. http://dx.doi.org/10.1016/0028-3932(87)90024-8 


\section{Figure captions}

Fig 1 - A representation of the two-dimensional target grid. The central fixation cross was 30 $\mathrm{cm}$ from the nearest edge of the display table to the participant

Fig 2 - A depiction of the various task conditions. All trials in all conditions began with the presence of a fixation cross which subsequently disappeared 200, 400 or $600 \mathrm{msec}$ before a target appeared. In the lift condition, participants simply lifted their hand; in the point fixation condition, they reached to where the fixation cross had been previously; and finally in the point target condition they would reach to where the target appeared

Fig 3 - Mean RTs for both hands across all three conditions. Clear main effects of both hand and condition are present, but there is no interaction. Error bars $=95 \%$ C.I.s

Fig 4 - Mean PVs and movement durations across the point fixation and point target conditions. A main effect of condition is present in both dependent measures, but no significant effect of hand was found 